\title{
Design and research of reclaimed water system in Chifeng College Dormitory
}

\author{
Qiang Li ${ }^{1}$, Yaxin Zhang ${ }^{1 *}$, Yafeng Zhang ${ }^{2}$, Qian Wang ${ }^{3}$, Xiaowei Li ${ }^{1}$, Ying Shuai ${ }^{1}$ \\ ${ }^{1}$ Departments of College of Physical and Intelligent Manufacturing Engineering, University of Chifeng, Chifeng, Inner Mongolia, China \\ ${ }^{2}$ Ningcheng Xinyuan water conservancy and Hydropower Engineering Company, Chifeng, Inner Mongolia, China \\ ${ }^{3}$ Division of employment and Entrepreneurship, University of Chifeng, Chifeng, Inner Mongolia, China
}

\begin{abstract}
With the continuous development of reclaimed water treatment technology, the development and research of wastewater treatment and reuse technology and equipment suitable for colleges and universities can not only eliminate the pollution of wastewater to the environment, but also reduce the cost of water use in Colleges and universities. The reclaimed water can be used as campus toilet and clean water. Chifeng College Dormitory water utilization system transformation, a lot of saving water and sewage charges, saving the water pipeline laying and operation of the corresponding facilities investment, corresponding to reduce the school operating costs.
\end{abstract}

\section{Introduction}

In view of the serious problem of water resources waste in Colleges and universities, governments and universities all over the country have taken a series of measures. Many provinces and cities are adjusting water prices, from the perspective of macro-control, raising water prices, so that people can save water. Colleges and universities have taken water-saving and energy-saving measures. For example, Tianjin water conservation management center and Nankai University School of environmental engineering and science set up a research group, designed the university water use questionnaire, through the Tianjin 22 Based on the investigation of the current situation of water use in Colleges and universities, the water-saving potential of colleges and universities is estimated quantitatively by quota comparison method, and corresponding water-saving measures are put forward to further tap the water-saving potential of colleges and universities. In addition, central China Normal University, Yili Normal University, Fuzhou University, Beijing University of technology and China University of science and technology have also publicized water conservation to make teachers, students and staff consciously save water; reform and improve water management, strengthen the construction of water use system; replace outdated and aging water appliances with water-saving and energy-saving sanitary appliances; and invest more funds to improve water supply Some water-saving and energy-saving measures have been taken in terms of equipment and infrastructure; water balance test is carried out irregularly; measurement network system is upgraded; and so on. But in terms of the actual situation of Chifeng University, reclaimed water recovery technology is an effective means to solve these problems[1-3].

\section{Reclaimed water recovery technology}

Reclaimed water reuse technology refers to the centralized treatment of domestic waste water (bathing, toilet, laundry, kitchen, toilet) to a certain standard and reused for greening irrigation, vehicle washing, road washing, toilet washing, etc., so as to achieve the purpose of saving water. Reclaimed water reuse can be used as the second source of water to improve the reuse rate of water. Reclaimed water reuse technology has been applied to practice in foreign countries. The United States, Japan and Israel are in the forefront of the world. These countries use reclaimed water as water for flushing toilets, farmland and landscaping irrigation, road cleaning, car washing, urban fountain, etc. Since the 1980s, Japan has vigorously advocated the use of reclaimed water, formulated various incentive measures, and actively promoted the reuse of reclaimed water. It also requires new government agencies, schools, enterprise office buildings, parks, stadiums and other public buildings to set up a reclaimed water system to use reclaimed water. At least seven areas in the United States have or are building reclaimed water reuse plants. The number of "reclaimed water reuse" in American schools has reached 17.08 times in 200 years, and the water consumption has decreased by $45 \%$. Israel is the country with the most characteristics in reclaimed water reuse. Israel is short of water resources, and its per capita water resources are only 476 cubic meters. Therefore, the urban water-saving countermeasures are adopted. $46 \%$ of the total amount of sewage treatment in China is directly reused for irrigation, and the remaining 33.3\%

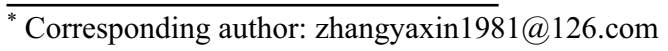


and about $20 \%$ are respectively recharged underground or discharged into rivers. The speed of reclaimed water reuse ranks first in the world[4-10].

At present, $100 \%$ of the domestic sewage and $72 \%$ of the urban sewage in Israel are recycled. It can be seen that many foreign countries have made great progress in reclaimed water reuse. Especially in Colleges and universities, in the 1980s, Japan required colleges and universities to set up reclaimed water system and use reclaimed water. China began to use reclaimed water since the end of 1990s. At present, it has a certain scale, but there is a big gap between China and developed countries. By 2009, China's sewage recycling rate (sewage recycling capacity / sewage treatment rate) will be about $15 \%$, while the ratio of sewage recycling to sewage discharge is only about 5\%. Beijing, Tianjin, Qingdao and other areas with serious water shortage are at the forefront of reclaimed water reuse, which are included in the overall urban planning. According to the overall planning of Beijing, nine medium-sized water plants will be built in the urban area in 2008, so that the reuse rate of reclaimed water can reach $50 \%$. Tianjin has also issued special regulations on the use of reclaimed water in residential buildings. New residential areas with an urban planning area of more than 50000 square meters and residential areas with a planned population of more than 10000 people must use reclaimed water and must be equipped with reclaimed water pipes. At present, some communities in Tianjin use reclaimed water to replace tap water for landscape water and green space irrigation. Qingdao is also a typical water shortage city. Facing the increasingly serious water shortage situation, Qingdao vigorously promotes the reuse of reclaimed water. At present, in China's universities, reclaimed water reuse has not been well popularized, but also has made certain achievements. For example, the reclaimed water treatment station of Beijing University of technology was built in 2003 with a design daily treatment capacity of $200 \mathrm{~m} 3$. The reclaimed water after biochemical treatment is mainly used for flushing toilets in student apartments, lawn greening on the north side of swimming pool, car washing and tree watering in gas stations. Yancheng Institute of technology began to pilot the reclaimed water reuse technology in the spring semester of 2002. The initial investment was more than 30000 yuan. Eight sets of reclaimed water reuse devices were made of stainless steel corrosion-resistant materials. They were used in an old dormitory building in the west campus. After practice and calculation, the cost was recovered in 10 months. Due to the remarkable effect of water-saving, it was fully promoted in the school in 2003. Over 400000 yuan was invested once. 118 sets of stainless steel reclaimed water reuse devices were installed in all the remaining 12 non apartment dormitory buildings, saving more than 200000 cubic meters in that year. At present, Northern Jiaotong University, Central University for Nationalities and Beijing United University have established reclaimed water treatment stations to realize the reuse of reclaimed water. Reclaimed water is recognized as the second water source in cities all over the world. To create a watersaving society and water-saving campus, we must attach importance to and develop reclaimed water reuse technology, and effectively use our second water source[11-17].

With the continuous development of reclaimed water treatment technology, the development and research of wastewater treatment and reuse technology and equipment suitable for colleges and universities can not only eliminate the pollution of wastewater to the environment, but also reduce the cost of water use in Colleges and universities. The reclaimed water can be used as campus road, toilet, flower watering and landscape water. However, it is imperative to study the reuse of reclaimed water under the condition of water shortage and serious waste. The realization of reclaimed water reuse has very important practical significance. It can not only alleviate the current situation of urban water resources shortage, but also save a lot of limited fresh water resources, so that water resources can be efficiently and sustainably utilized. Reclaimed water reuse is also an effective way to reduce sewage discharge, which can greatly reduce the amount of sewage discharge, reduce the degree and scope of pollution to natural water body, and accordingly reduce the pollution degree and scope of natural water body The investment in the treatment of environmental pollution is low, which has certain economic benefits[18-21].

\section{Coverall Strategy}

The reclaimed water utilization system of Chifeng university includes wastewater collection system and reclaimed water utilization system. The wastewater collection system includes urinal water collection system and washing wastewater collection system.

The urinal water collection system is shown in Figure 1. The urinal water collection system collects urine and urine flushing water. These pools can be used as reclaimed water for the next floor of the toilet.

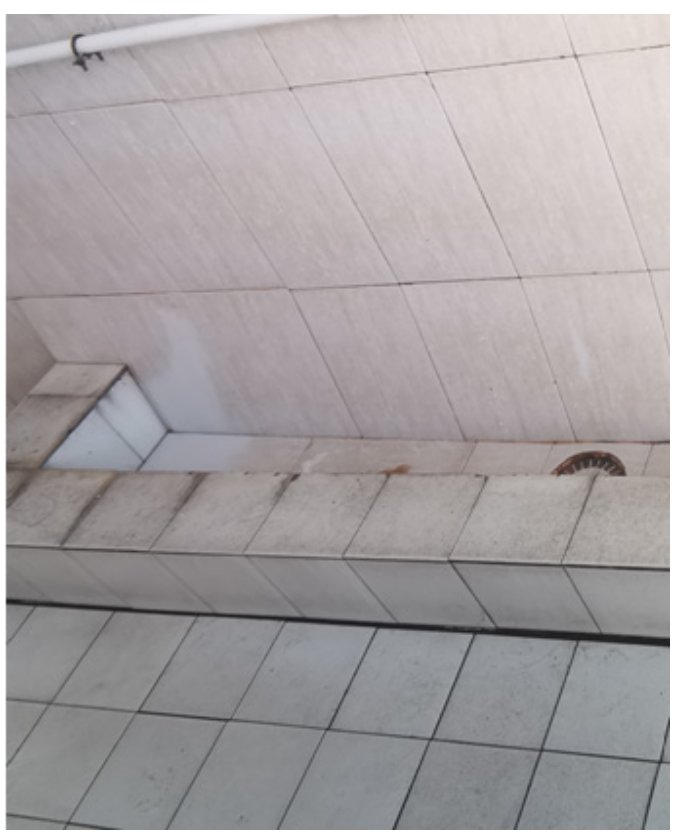

Figure 1 Urinal water collecting device 
The washing wastewater collection system is shown in Fig. 2, which mainly collects washing water. The recycled wastewater can not only be used as flushing water for the next floor of toilet, but also can be used for floor dragging after filtration treatment.

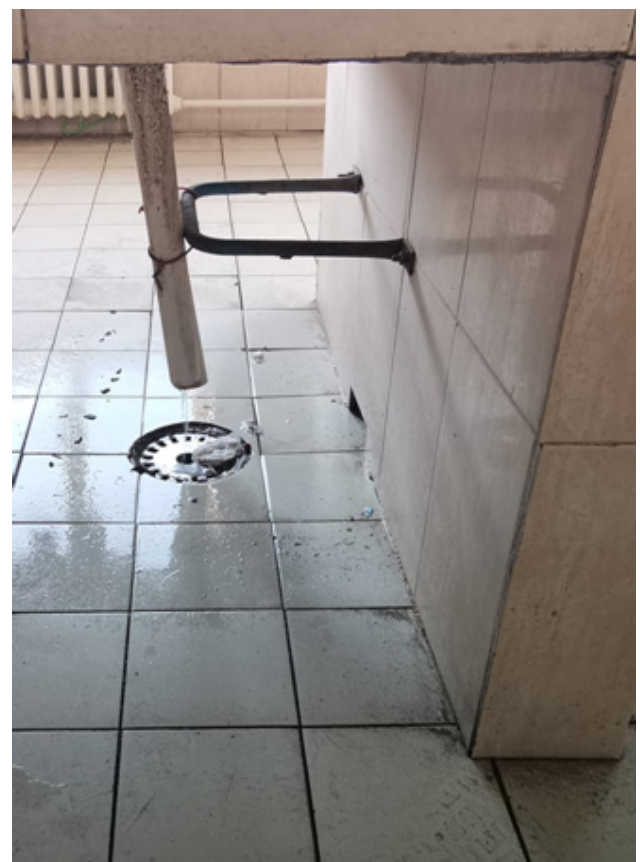

Fig. 2 Collection of washing wastewater

The reclaimed water from the upper floor of the dormitory is mainly used for flushing the next floor of the toilet, as shown in Figure 3. After being stored by the water storage system, it can basically meet $50 \%$ of the flushing water consumption at peak and $100 \%$ at off peak.

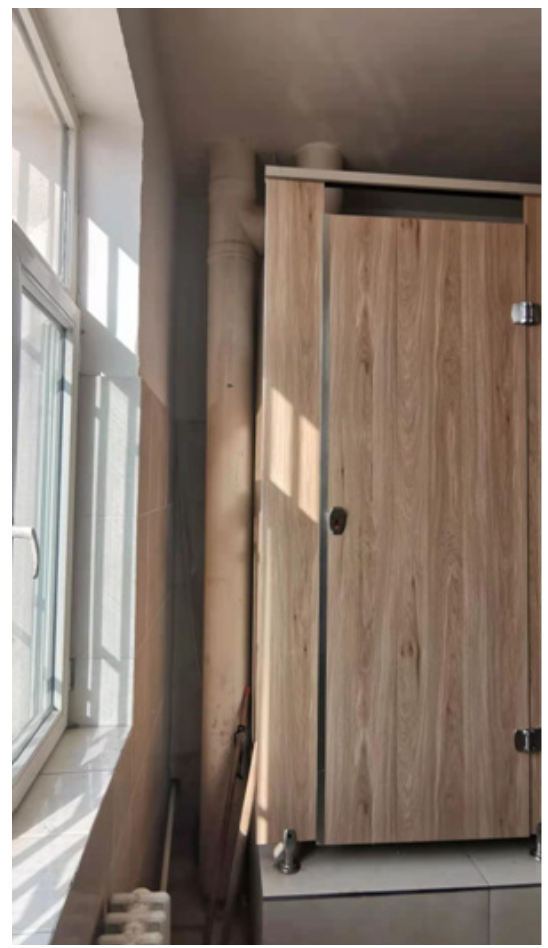

Fig. 3 Use of untreated reclaimed water
The reclaimed washing water on the upper floor of the dormitory is treated with purified water, as shown in Figure 4 . The treated reclaimed water can be used as the mop water for the next floor, as shown in Figure 5.

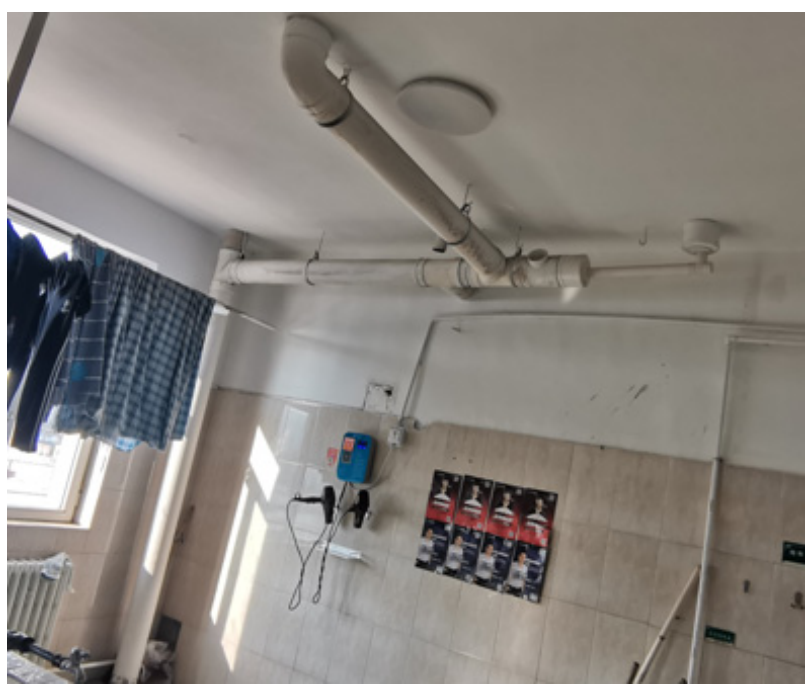

Figure 4 Simple treatment system of reclaimed water

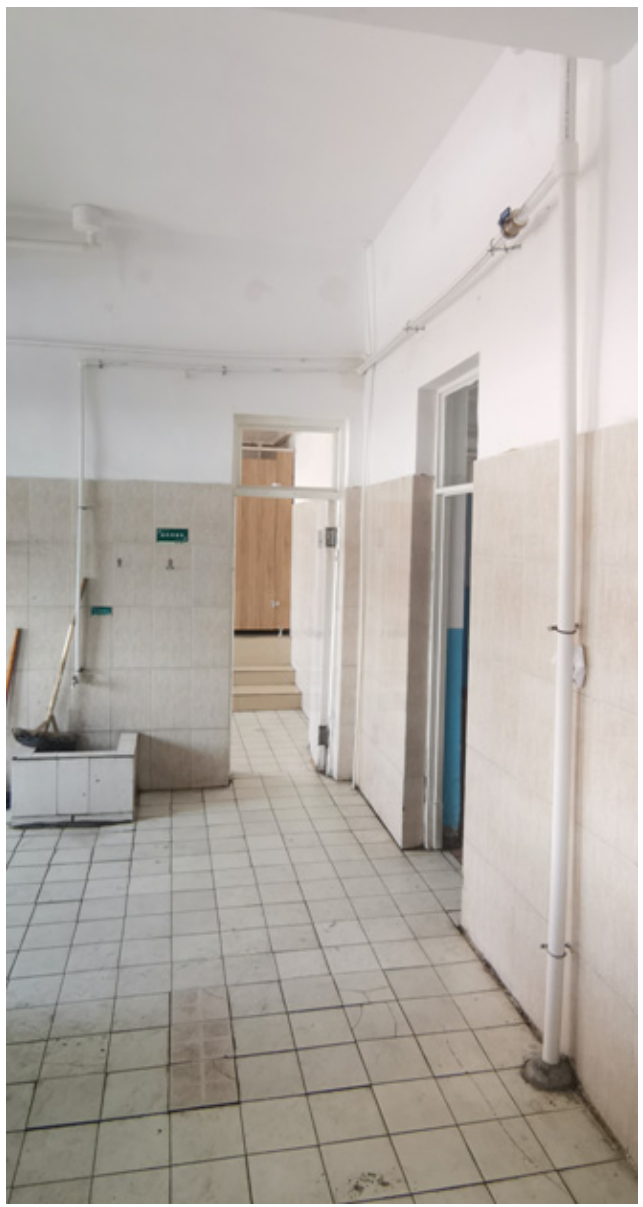

Figure 5 Reclaimed water utilization system after filtration treatment

\section{Conclusion}

The water conservancy network system in Chifeng College Dormitories saves a lot of water and sewage 
charges, saves the cost of water pipeline laying and operation and other corresponding facilities, and correspondingly reduces the operation cost of the school. Practice has proved that it is an economic, convenient and feasible choice to treat and reuse reclaimed water, which can greatly improve the utilization rate of water resources. Therefore, it is necessary to vigorously promote the use of reclaimed water in Colleges and universities.

\section{Acknowledgments}

This work was supported by Chifeng College Students' innovation and entrepreneurship training program in 2020 (DCXM2020014).

\section{References}

1. Wang Jianzhong. Research on reclaimed water treatment and reuse technology in green buildings [J]. Shanghai construction technology, 2013, (02): 27-30

2. Yang Maogang, Zhao Shuqi, Wang Qianxun, Chen Shuzhen. Review on the development of reclaimed water utilization abroad [J]. Haihe Water Conservancy, 2013, (8): 30-33

3. Zhu Li, sun Limi. Application of underground infiltration in sewage treatment of University Park [J]. Water supply and drainage, 2007, (6): 96-98

4. Tong Jianping, Wang Hongyan, Ren Yongzheng. Treatment of Campus Domestic Sewage by biological contact oxidation / constructed wetland process $[\mathrm{J}]$. China water supply and drainage, 2008, (12): $52-54$

5. Nong Qiuyue, Wang dunqiu, Hua Wenqiang, you Shaohong, Kato Xiusheng, Zhang Wenjie. Pilot scale test of reclaimed water reuse in Winter Campus Sewage Treatment by c-mbr system [J]. Water treatment technology, 2014, (1): 114-117

6. Zhang Baojie, Wang Gang, Shi Yuming, Li Gang. Study on effluent quality of MBR reactor [J]. Journal of Harbin Jianzhu University, 2002,35 (4): 56-59

7. Liang Wei. Design of reclaimed water reuse system in Taiyuan University of technology [J]. Shanxi architecture, 2010, (29): 165-166

8. Zhao Jielin. Analysis of urban rainwater resources utilization in Shanxi Province [J]. Shanxi Water Conservancy Science and technology, 2010, (02): 68-70

9. Su Yu, Dong Hongxiang, Zhang Zhenhua. Research on green campus construction in Higher Vocational Colleges [J]. Ningxia Agricultural and forestry science and technology, 2013, (08): 80-91

10. Zhou Jinshuo. Intelligent analysis of energy-saving construction of a university green campus -Discussion on the planning of green campus in Colleges and universities in China [J]. Resource conservation and environmental protection, 2013, (12): $15-16$

11. Zhu Yaohua. Creating green campus culture $[\mathrm{J}]$. Teaching and educating people, 2009, (11): 112-114

12. $\mathrm{Xu}$ Jin. Green campus: the low carbon road of Tongji University [J]. Landscape, 2010, (10): 88-90

13. Lu Bin. International comparison of goals and measures of green campus construction [J]. Construction technology, 2013, (12): 30-36

14. $\mathrm{Xu}$ Xiaowei. Green building and green campus construction $[\mathrm{J}]$. China modern education equipment, 2014, (10): 34-37

15. Wu Zhiqiang, Wang zisong. Green Campus - for our common future - work of green campus group of China Green Building and energy conservation professional committee [J]. Construction technology, 2013, (12): 16-19

16. Li Anfeng, pan Tao, Li Jian. Wastewater treatment and recycling project of a university $[\mathrm{J}]$. China water supply and drainage, 2013, (8)

17. Huang Yechun. Discussion on sewage treatment transformation in University District [J]. Technology and market, 2014, (6): 52-53

18. Cui Jiangtao. Study on sewage discharge characteristics and constructed wetland treatment technology of college students [D]. Hunan: Master's thesis of Hunan Agricultural University, 2013:4

19. Wu Tao e ,Zhang Yuan fu , Zhou Mingfa . On Establishment of Water Recycling System Optimum Planting in University[C]. Proceedings of 2012 International Conference on Computer Science and Mathematics,Physical Education and Management (ICCMPE 2012).

20. Wang Qian. Developing Water Culture Research and Education in Water Conservancy Colleges is inevitable for Water Conservancy Higher Education[C]. Proceedings of 2013 International Conference on Psychology,Management and Social Science(PMSS 2013) Volume 16, 2013.

21. Thormark C. Conservation of energy and natural resources by recycling buildingwaste[J]. Resources, Conservation and Recycling,2001,33(2) : 313-130. 